\title{
Saying What's on Your Mind: Working Memory Effects on Sentence Production
}

\author{
L. Robert Slevc \\ University of Maryland, College Park
}

\begin{abstract}
The role of working memory (WM) in sentence comprehension has received considerable interest, but little work has investigated how sentence production relies on memory mechanisms. Three experiments investigated speakers' tendency to produce syntactic structures that allow for early production of material that is accessible in memory. In Experiment 1, speakers produced accessible information early less often when under a verbal WM load than when under no load. Experiment 2 found the same pattern for given-new ordering (i.e., when accessibility was manipulated by making information given). Experiment 3 addressed the possibility that these effects do not reflect WM mechanisms but rather increased task difficulty by relying on the distinction between verbal and spatial WM: Speakers' tendency to produce sentences respecting given-new ordering was reduced more by a verbal than by a spatial WM load. These patterns show that accessibility effects do in fact reflect accessibility in verbal WM and that representations in sentence production are vulnerable to interference from other information in memory.
\end{abstract}

Keywords: language production, grammatical encoding, working memory, accessibility effects, similarity-based interference

A fundamental difficulty with producing language is that nonlinear conceptual information must be expressed as a linear order of words. This transformation happens at the level of grammatical encoding, where selection and retrieval of content words interface with structure building processes. By most models of language production, grammatical encoding involves two subprocesses: Content processing involves mapping the semantic aspects of a to-be-expressed message onto syntactically based lexical representations (termed lemmas), which then point to metrical and phonological information (word forms or lexemes). Structure processing involves mapping the relational aspects of the message (i.e., who did what to whom) onto grammatical functions (e.g., subject and direct object) and the sequential ordering of constituents (for further detail on this consensus model of grammatical encoding, see Bock, 1995; Ferreira \& Slevc, 2007; Levelt, Roelofs, \& Meyer, 1999). Because content retrieval proceeds relatively independently of structural processing and because lexical retrieval is a variable process, there will often be a discrepancy between the order in which lexical content is retrieved and the order in which that content must be produced (Bock, 1982). Consequently, speakers often must temporarily maintain lemmas and word forms in working memory (WM) until they can be grammatically produced.

This article was published Online First July 18, 2011.

This research was supported by National Institutes of Health Grants R01 HD-051030 and F32 DC-008723. It has benefited from the helpful comments and advice of many people, including Kay Bock, Jeremy Boyd, Tamar Gollan, Liane Wardlow Lane, and especially Vic Ferreira. Additionally, I thank Stephanie Ang, Serina Chang, Ruby Cho, Katie Doyle, Paige Heath, Ramsey Khouri, Yanny Siu, and Neil Spears for assistance with data collection.

Correspondence concerning this article should be addressed to L. Robert Slevc, Department of Psychology, University of Maryland, College Park, MD 20742. E-mail: slevc@umd.edu
WM is generally assumed to be a limited-capacity system, so there is pressure on speakers to minimize demand on WM by not maintaining to-be-produced lexical representations any longer than necessary. Thus, speakers could benefit by choosing structures that allow them to produce retrieved lexical representations as soon as they are grammatically able, which motivates the otherwise puzzling phenomenon that languages often offer more than one way to say the same thing (Ferreira, 1996). For example, imagine that a speaker wanted to convey information about a pirate agent, a monk patient, and a book being given (setting aside for now exactly why someone would want to convey this information). If the speaker retrieved "book" before "monk," she might benefit by using a prepositional dative structure (The pirate gave the book to the monk), whereas if she retrieved "monk" before "book," she might benefit by using a double-object dative structure (The pirate gave the monk the book).

In fact, speakers do tend to choose structures allowing for earlier production of easier-to-retrieve information. Evidence for these accessibility effects comes from experiments showing that speakers tend to misrecall sentences as having syntactic structures in which more accessible items occur early (Bock \& Irwin, 1980; Davidson, Zacks, \& Ferreira, 2003; Ferreira \& Yoshita, 2003). This is true when the items are easier to access both conceptually and lexically, but other work has shown that conceptual accessibility alone can affect syntactic choice. For example, speakers tend to choose syntactic structures allowing for early production of information that is more imageable (Bock \& Warren, 1985), that is animate (McDonald, Bock, \& Kelly, 1993), or that is semantically primed (Bock, 1986). The few studies that have directly addressed the effect of formal accessibility on speakers' choice of syntactic structures have found little or no effect (Bock, 1987; Levelt \& Maassen, 1981; McDonald et al., 1993), suggesting that formbased accessibility is not a very relevant factor at the point when 
a speaker must commit to a particular syntactic structure. Thus, the accessibility of message-level information and of lemmas appears to influence syntactic choice, but the accessibility of phonological word forms does not.

Of course, accessibility is only one of many factors contributing to variations in syntactic structure (see, e.g., Bresnan, Cueni, Nikitina, \& Baayen, 2007). Another important factor in syntactic choice is the information structure of a sentence (e.g., Halliday, 1970). Most relevant to the current discussion, things that are given (exact definitions vary, but given information uncontroversially includes what has been previously mentioned in the discourse) tend to be mentioned earlier than things that are new, a phenomenon termed given-new ordering (Bock, 1977; Chafe, 1976; Gundel, 1988; Halliday, 1970; Smyth, Prideaux, \& Hogan, 1979). Given information also tends to be relatively accessible, and so given-new ordering can, at least in some circumstances, result from the same factors that lead to accessibility effects (Arnold, Wasow, Losongco, \& Ginstrom, 2000; Bock \& Irwin, 1980; Branigan, McLean, \& Reeve, 2003). ${ }^{1}$

As suggested above, a plausible explanation for these accessibility effects (and at least some instances of given-new ordering) is that they result from pressures on WM. However, there is as yet no evidence that actually shows this to be the case. In fact, there is relatively little work investigating the role of WM in any aspect of language production. There is a small body of research showing that WM processes are involved in lexical access (Belke, 2008; Daneman, 1991; Daneman \& Green, 1986; for evidence from written production, see Kellogg, 2004), and there is other work linking short-term memory processes (including WM) to the scope of planning in production (R. C. Martin \& Freedman, 2001; R. C. Martin, Miller, \& Vu, 2004; Wagner, Jescheniak, \& Schriefers, 2010), to syntactic agreement processes (Badecker \& Kuminiak, 2007; Bock \& Cutting, 1992; Hartsuiker \& Barkhuysen, 2006), and to aspects of discourse processing and audience design (Arnold, 2010; Arnold \& Griffin, 2007; Horton \& Gerrig, 2005a, 2005b; Roßnagel, 2000, 2004).

The goal in the present experiments was to investigate whether and how accessibility effects reflect WM processes. The experiments have basically the same design, in which participants described dative-eliciting pictures after either the theme (the direct object) or the goal argument (the indirect object) was made accessible or given. The main task was to describe pictures (e.g., of a pirate, a monk, and a book being given) from a poster on the wall. Participants knew which picture to describe on each trial because the experimenter first asked a question about an agent (e.g., What's going on with the pirate?), thus limiting responses to a subset of pictures containing that agent, and the participant was given a cue, which was the theme or goal argument (book or monk). This uniquely identified a single picture that the participant then described. The presentation of the cue word was also intended to increase the accessibility of one of the postverbal noun phrases, and so participants were expected to show accessibility effects by tending to produce structures in which the cued item was produced relatively early. Participants performed this task as described and also while under a concurrent verbal WM load to determine how accessibility effects depend on WM.

One way to think of accessibility effects is as a metaphorical "release valve" for WM. By this account, when a speaker is describing a picture of a pirate, a monk, and a book being given and the theme concept and lemma (book) are active in WM by virtue of having been previously seen or mentioned, the speaker can reduce demand on her limited-capacity WM system by producing the theme relatively early in a prepositional dative structure (The pirate is giving the book to the monk) rather than maintaining the theme in WM for relatively longer in order to produce a double-object dative structure (The pirate is giving the monk the book). (It should be noted that this is presumably an unconscious effect, not a conscious strategy.) This account fits with models of WM as a limited-capacity workspace or buffer (e.g., Baddeley, 1986; Jackendoff, 2002; Just \& Carpenter, 1992; R. C. Martin, Lesch, \& Bartha, 1999) in which the accessible information is produced early to free WM capacity that could otherwise be devoted to other processes. This logic is similar to the idea that the recency effect in list recall reflects the utility of quickly producing those items still active in short-term or primary memory (Davelaar, Goshen-Gottstein, Ashkenazi, Haarmann, \& Usher, 2005; Glanzer \& Cunitz, 1966; but see Crowder, 1982, 1993). Accessibility effects should thus be particularly helpful when WM resources are low, so a concurrent load on verbal WM should lead to an increase in accessibility effects.

A different way to conceptualize accessibility effects comes from work looking at the intrinsic properties of information (e.g., imageability or animacy) that make that information easy to retrieve (e.g., Bock \& Warren, 1985; McDonald et al., 1993). These findings suggest that accessibility effects might reflect ease of lexical retrieval by WM mechanisms rather than reflect a pressure to free WM capacity. A focus on retrieval fits with recent models of WM that conceptualize WM as having an extremely limited capacity for active maintenance in focused attention (perhaps even as limited as one item; McElree, 2001) but as having an important role in managing the retrieval of information from a set of activated (nonfocused) information in long-term memory (e.g., Cowan, 2001; Lewis, 1996; Oberauer, 2002; Unsworth \& Engle, 2007). By these accounts, the activated set of long-term memory is not capacity limited per se; instead, access to this nonfocused information is subject to retrieval interference from other active, cue-relevant information. Given this conception of WM, accessibility effects reflect the utility of quickly producing easily retrieved information that could otherwise be subject to interference at retrieval.

According to this retrieval-based account of accessibility effects, maintaining a concurrent verbal WM load places additional potentially interfering information in the activated subset of longterm memory (or perhaps even in the focus of attention as a verbal load is being rehearsed). Thus, when a speaker is describing a picture (again, of a pirate agent, a monk patient, and a book being given) and one of the postverbal arguments (monk or book) is easier to retrieve by virtue of having been previously seen or mentioned, she should tend to choose a structure allowing that information to be produced early. However, when the speaker is

\footnotetext{
${ }^{1}$ This distinction between given and new is similar to the division between theme and rheme and between focus and presupposition (Jackendoff, 1972), all of which are often grouped together under the broader terms topic and comment. Although at least some of these concepts are dissociable (e.g., Halliday, 1994), information that is given, theme, focused, and/or topic is likely also to be relatively accessible.
} 
also maintaining a verbal WM load, the accessibility of the previously seen or mentioned item (monk or book) is likely to be moderated by interference from this WM load; thus, she should show a lesser tendency to produce that item early. That is, a verbal WM load should lead to a reduction in accessibility effects if the relevant WM limitation is interference but an increase in accessibility effects if the relevant limitation is capacity.

There are at least two additional possibilities. In light of arguments that syntactic parsing relies on a syntax-specific form of WM (a claim most strongly associated with Caplan and Waters, 1999), speakers' choices between syntactic alternatives in production might also rely on syntax-specific WM. If so, a concurrent verbal WM load should have no effect on accessibility effects. A quite different claim comes from arguments that many purportedly WM-based effects actually reflect very general processing constraints, such as the ability to actively maintain task goals and/or to control attention (e.g., Kane et al., 2004; McCabe, Roediger, McDaniel, Balota, \& Hambrick, 2010; Unsworth \& Spillers, 2010; Vergauwe, Barrouillet, \& Camos, 2010). These arguments suggest that a verbal WM load might affect accessibility effects not because of WM processes per se but rather because of general attentional demands. Thus, this account predicts that any type of concurrent cognitive load (even a nonverbal load) would interact with accessibility effects.

\section{Experiment 1}

The goal in Experiment 1 was to test the idea that accessibility effects on syntactic choice result from WM processes. To this end, participants described dative-eliciting pictures for which the name of either the theme or the goal constituent was made accessible, and they did so with or without a concurrent WM load. Participants' primary task was to describe pictures from a poster on the wall (e.g., of a pirate agent, a monk patient, and a book being given). On each trial, participants heard a question that indicated the agent in the to-be-described picture (What's going on with the pirate?) and then saw a visually presented cue on a computer screen that indicated another piece of information in the picture (here, book or monk). Together, these pieces of information uniquely identified one picture, and the visual cue additionally increased the accessibility of the theme (if the cue was book) or the goal (if the cue was monk). On WM load trials, participants read two unrelated words at the beginning of the trial and had to recall those words after producing their sentence.

\section{Method}

Participants. Forty-nine students at the University of California, San Diego, participated in exchange for class credit. Data from one participant were excluded because of an equipment malfunction. All participants reported English as their native language.

Materials and design. Experimental materials for the dativeeliciting task consisted of 24 pictures of dative actions with dative verbs printed underneath. Twelve dative verbs were used, each with two pictures. An additional 12 pictures of transitive actions with transitive verbs printed underneath were used as filler items. These 36 pictures were printed on a poster, approximately $1 \mathrm{~m}$ square, in six rows of six pictures each. The pictures in each row had the same agent but different themes and goals (and patients, in the case of the two fillers in each row). In each row, half of the pictures were oriented with the subject on the right and half were oriented with the subject on the left. Two additional filler pictures were printed on a separate sheet of paper and were used for examples and practice during the instructions.

Each picture was paired with a cue word (the name of the theme or goal argument) and both with and without a WM load of two unrelated words. Thus, there were four versions of each item, which were counterbalanced across four lists such that each item appeared an equal number of times in each condition across the experiment and such that each participant was presented with each item only once.

Procedure. The experiment was administered with PsyScope 1.2.5 (Cohen, MacWhinney, Flatt, \& Provost, 1993). Participants sat facing the computer screen, and the experimenter sat beside the participant such that the computer screen was obscured from the experimenter's view by a cardboard divider. Both the participants and the experimenter could easily see the poster of line-drawn pictures.

Each experimental session lasted about 30 minutes, beginning with instructions and administration of two practice items, which were not used in the experimental trials. In the experimental trials, participants described dative-eliciting pictures from a poster on the wall (e.g., of a pirate giving a monk a book) in response to spoken questions and visually presented cues. On each trial, the experimenter would ask a question about the agent in a subset of the pictures (e.g., What's going on with the pirate?). Participants would then read a word corresponding to one of the postverbal noun phrases in a specific picture (e.g., BOOK or MONK) on the computer screen (which was not visible to the experimenter), thereby making that noun phrase more accessible and also allowing participants to find the appropriate picture to describe (i.e., the picture that includes both the subject from the question and the object named on the computer screen). Participants then described the appropriate picture to the experimenter by saying a sentence that started with the same noun phrase that the experimenter used in the question (participants were asked to avoid using pronouns) and included the verb printed under the picture. On half of the trials, participants were first presented with a WM load of two unrelated words, shown in boldfaced, blue, 14-point font, which they were instructed to remember and recall aloud in any order when prompted at the end of the trial. Trials occurred in a fixed pseudo-random order, constrained such that no more than two consecutive questions were about the same agent and no more than three consecutive trials were of the same WM-load condition.

Analysis. Participants' sentences from the picture-description task were transcribed and coded as prepositional datives or doubleobject datives. Trials in which participants did not produce a dative sentence, did not produce a full subject noun phrase, did not produce both postverbal noun phrases, or did not produce the appropriate verb were excluded from the analysis, causing $9.7 \%$ of all critical trials to be excluded (10.2\% of trials in the WM-load condition and $7.8 \%$ of trials in the no-load condition). Additionally, trials in which participants did not correctly recall at least one word of the WM load were excluded, eliminating another $2.4 \%$ of trials in the WM-load condition.

In this and in all experiments reported here, data were analyzed with orthogonal contrast coding in logistic generalized linear 
mixed-effects models as implemented in the lme4 package (Bates \& Maechler, 2009) in the statistical software R (Version 2.9.1; R Development Core Team, 2009). Cue type (theme or goal) and WM load were included as fixed effects, and random intercepts were included for participants and for items; however, random effects are not reported, as only the fixed effects tests were of interest. Parameter estimates were calculated with maximum likelihood modeling using Laplace approximations, and the statistical significance of individual fixed-effect estimates was determined with the Wald $z$ statistic. For readability and for purposes of graphical presentation, values are described as proportions rather than as log-odds ratios.

\section{Results and Discussion}

Figure 1 shows the proportion of prepositional datives produced as a function of cue type (theme or goal) and WM load (none vs. two words). Participants were numerically more likely to produce prepositional datives following theme than goal cues, but this main effect reached only marginal significance $(b=0.37, S E=0.20$, $z=1.82, p<.10)$. There was no main effect of WM load $(b=$ $-0.09, S E=0.10, z=-0.46$ ); however, cue type and WM load interacted significantly $(b=-0.80, S E=0.40, z=-2.00, p<$ $.05)$. As shown in Figure 1, this interaction reflects participants' tendencies to produce the cued noun phrase early only when not under a concurrent WM load: Participants showed an $8 \%$ accessibility effect in the no-load condition (shown by a significant simple main effect of cue type within the no-load conditions, $b=$ $0.76, S E=0.28, z=2.73, p<.01$ ) but no effect in the concurrent two-word load condition (a nonsignificant $-1 \%$ simple main effect, $b=-0.03, S E=0.28, z=-0.12)$.

One might have expected more accurate WM load recall when the cued noun phrase was produced early (i.e., when early production presumably led to reduced interference during retrieval of the load words); however, there was no effect of constituent order on WM load accuracy $(b=0.73, S E=1.02, z=0.71)$, reflecting participants' very accurate recall of load words both when the cued noun phrase was produced early $(98.8 \%$ correct) and when the cued noun phrase was produced late $(97.6 \%$ correct).

These data show an interaction between accessibility effects and verbal WM load and thus provide clear evidence that accessibility effects rely on WM. Based on the motivation of accessibility effects as a WM release valve that eases production, it is surprising that accessibility effects disappeared when under WM load, when production was presumably most difficult. Instead, this pattern suggests, accessibility effects are susceptible to interference from other items in memory, which is consistent with models of WM that posit only a very limited ability for active maintenance plus an interference-susceptible, cue-based retrieval process (e.g., Cowan, 2001; Lewis, 1996; Unsworth \& Engle, 2007). That is, the WM load presumably led to increased interference during lexical retrieval, thus reducing or eliminating the differential accessibility of the cued item. Experiment 2 aimed to replicate this effect using a more ecologically valid form of accessibility, specifically, manipulating whether information was given (by virtue of having been previously mentioned) or new.

\section{Experiment 2}

As mentioned in the introduction, speakers not only tend to mention more accessible information early but also tend to order given information before new information. Given-new ordering is, by some accounts, a manifestation of audience design; that is, speakers use given-new ordering in order to facilitate comprehension by their listener (e.g., Ariel, 1991; Clark \& Haviland, 1977). Others argue that given-new ordering is not necessarily based on a cognitive model of the listeners' knowledge but occurs simply because information that is given (by, for example, previous mention or perceptual salience) is often also relatively more accessible than new information (Bock \& Irwin, 1980; Branigan et al., 2003). In either case, when something is given, it is likely also to be highly accessible. Based on the results of Experiment 1, this predicts that speakers' tendency to produce given-new ordering should also be reduced when under a WM load.

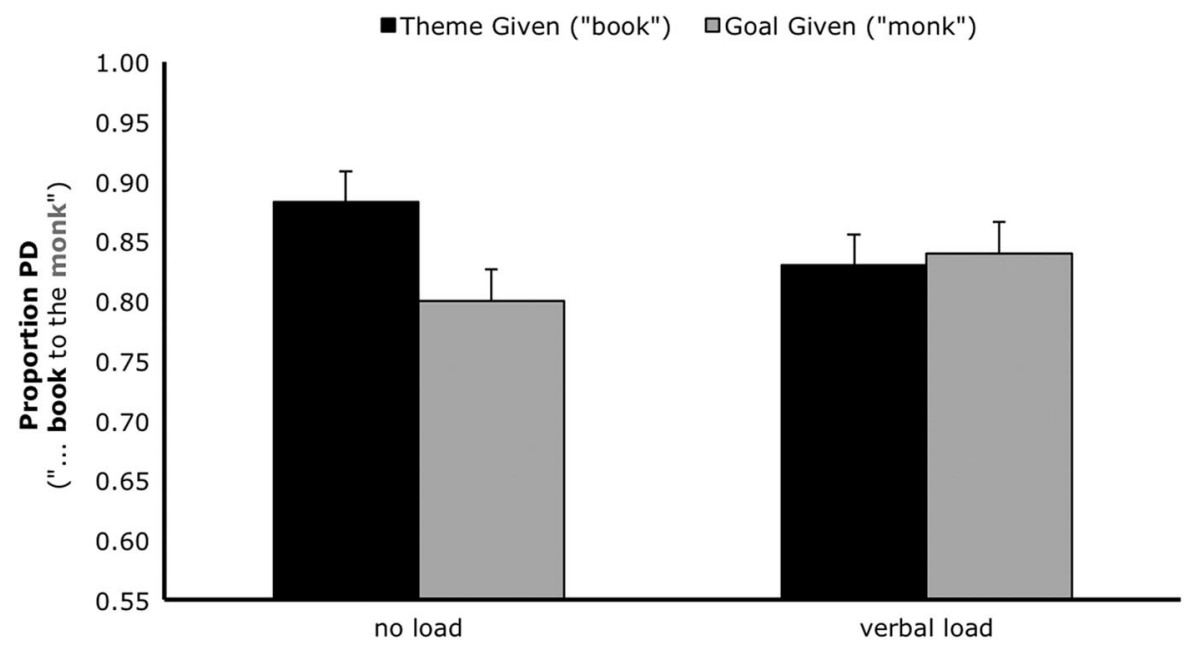

Figure 1. Proportion of prepositional dative (PD) sentences produced in Experiment 1 as a function of cue type (i.e., which postverbal argument was made accessible: theme or goal) and WM load (none or two-word load). Note that the $y$-axis does not start at zero. Error bars represent standard error. 


\section{Method}

Participants. Forty-eight students at the University of California, San Diego, participated in exchange for class credit. All participants reported English as their native language.

Materials, design, and procedure. The experimental design and materials were identical to those used in Experiment 1. The procedure was similar to that of Experiment 1, with one major exception: Instead of the accessibility of a postverbal noun phrase being manipulated by showing that word on a computer screen that was privileged to the participant, one postverbal argument was made, given by the experimenter. Participants described pictures (e.g., of a pirate giving a book to a monk) in response to questions asked by the experimenter, who manipulated the given argument by mentioning one of the postverbal noun phrases (contrast sentences 1 and 2).

1. What's going on with the pirate and the book?

2. What's going on with the pirate and the monk?

The experimenter sat facing away from the poster (unlike in Experiment 1) so that the pictures themselves would not be construed as being given information, and the given argument was always referred to with the definite determiner the, which is consistently related to givenness (Grieve, 1973). On WM load trials, the experimenter first said aloud two unrelated words for participants to maintain throughout the question and picture description. Finally, participants read instructions from a sheet of paper instead of from the computer screen.

\section{Results and Discussion}

Following the same criteria used in Experiment 1, trials in which participants did not produce a dative sentence, did not produce both postverbal noun phrases, or did not produce the appropriate verb were excluded (accounting for $5.9 \%$ of trials in each WMload condition), as were trials in which participants did not recall at least one word of the WM load (resulting in exclusion of an additional $8.3 \%$ of trials in the WM-load condition).

Figure 2 shows the proportion of prepositional datives produced as a function of WM load (none vs. two words) and cue givenness (theme or goal). As can be seen, results were similar to those of Experiment 1 but with bigger differences overall. A main effect of cue givenness $(b=1.62, S E=0.21, z=7.72, p<.001)$ reflected participants' tendency to produce given information before new information. There was no main effect of WM load $(b=-0.10$, $S E=0.20, z=-0.50)$, but the effect of cue givenness was reduced when participants were under a concurrent WM load, as shown by a significant Cue Givenness $\times$ WM Load interaction $(b=-0.84$, $S E=0.41, z=-2.07, p<.05)$.

These results show that a verbal WM load influences given-new ordering in essentially the same way that it influences accessibility effects (in Experiment 1): by leading to a reduction in speakers' tendency to produce given information early. This pattern is as predicted by retrieval models of WM but is inconsistent with syntax-specific or workspace models of WM. A statistical comparison of Experiments 1 and 2 with cue manipulation (experiment) used as a between-subjects factor (i.e., whether cues were made accessible or given) revealed only one effect involving cue manipulation: an interaction with cue type $(b=1.16, S E=0.29$, $z=4.04, p<.001)$. This shows that making a cue given had a greater effect on constituent ordering than did making a cue accessible (a $16.9 \%$ effect of cue givenness in Experiment 2 vs. a $3.4 \%$ effect of cue accessibility in Experiment 1), but the ways in which a WM load affected accessibility effects and given-new ordering did not differ. That cue manipulation was not involved in any other effects or interactions suggests that the manipulation of givenness used in Experiment 2 was essentially acting as a strong manipulation of accessibility.

Unlike in Experiment 1, participants' memory for the WM load was affected by constituent order: Participants accurately recalled at least one of the two words on every trial in which they had produced a sentence with given before new information but on

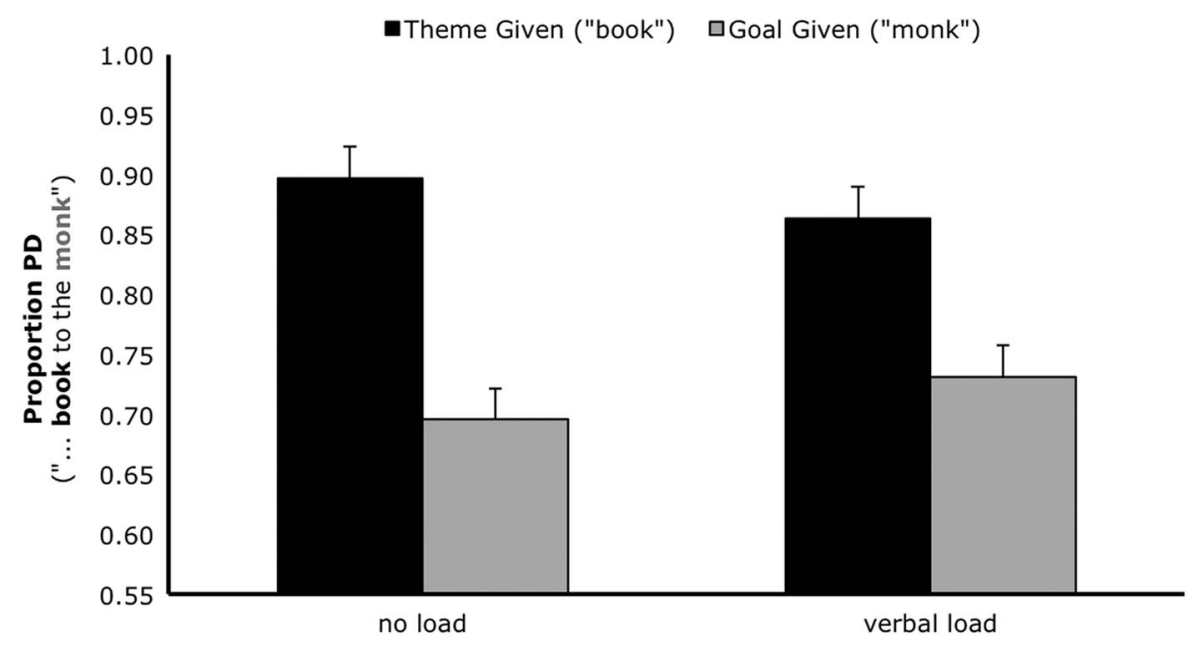

Figure 2. Proportion of prepositional dative (PD) sentences produced in Experiment 2 as a function of cue givenness (i.e., which postverbal argument was given information: theme or goal) and working memory load (no load or two-word load). Note that the $y$-axis does not start at zero. Error bars represent standard error. 
only $81.6 \%$ of the trials on which they produced a sentence with new before given information $\left(\chi^{2}=106.5, p<.001\right){ }^{2}$ This provides further support for the idea that choosing a syntactic structure that allows for early mention of accessible information can, in fact, reduce demand on WM. When speakers were able to produce the cued item early, this presumably allowed for active maintenance of other items and also prevented that cued item from interfering with the retrieval of the WM load words. When the cued item was not produced early, it presumably was maintained for a longer time in the small window of active maintenance or had to be retrieved for later production. In either case, there was more opportunity for the cue word to interfere with retrieval or maintenance of the WM load.

In addition, these results suggest that the modality of WM load presentation was not important in these experiments, as the auditorally presented WM load in Experiment 2 produced the same pattern of effects as did the visually presented WM load in Experiment 1 .

\section{Experiment 3}

Although in Experiments 1 and 2 a WM load was found to reduce speakers' use of accessibility effects and given-new ordering, it is possible that these results arise not from a load on WM per se but simply because the experimental task is more complicated or demanding on the WM load trials. For example, perhaps participants were less affected by manipulations of accessibility and givenness in the WM load conditions simply because the load trials effectively imposed a dual task (cf. Pashler, 1994; for a similar alternative explanation applied to other studies, see Caplan \& Waters, 1999). This explanation fits with evidence that WM capacity at least partially reflects the ability to control attention (e.g., Kane et al., 2004; Unsworth \& Spillers, 2010) and suggests that general attentional control (not interference in verbal WM per se) might underlie these grammatical encoding processes.

There is, however, a straightforward way to address this possibility. WM theorists have pointed to an important distinction between verbal and spatial WM (e.g., Baddeley, 1986; Baddeley \& Hitch, 1974; Friedman \& Miyake, 2000; Shah \& Miyake, 1996, but see Vergauwe et al., 2010), and most work suggesting a role of WM in syntactic processing has, at least implicitly, claimed that language processing involves verbal but not spatial WM (e.g., Fedorenko, Gibson, \& Rohde, 2007; Jackendoff, 2002; although note that some aspects of language processing may be inherently spatial; e.g., Chatterjee, Southwood, \& Basilico, 1999; Richardson, Spivey, Barsalou, \& McRae, 2003). ${ }^{3}$ If verbal and spatial WM are separate subsystems, an external load on verbal WM should affect accessibility effects, but a load on spatial WM should not. Frameworks that define WM in terms of processes that act on long-term memory representations and that point to WM's susceptibility to interference (Cowan, 1999, 2005; Lewis, 1996; McElree, 2001; Unsworth \& Engle, 2007) make the same prediction, although for different reasons. In particular, these models claim that the same system is used for both phonological and spatial maintenance; however, because interference occurs between representations that are similar, a load that is quite different from the primary task materials should not interfere with that task (see also Guérard \& Tremblay, 2008).
Experiment 3 had two parts. The first part of Experiment 3 was identical to Experiment 2 except that the no-load trials were replaced with spatial load trials. The second part required participants to perform a spatial task (mental rotation) under the same two WM-load conditions (verbal or spatial). The spatial load was a pattern memory task matched in difficulty to the verbal load, as determined in a previous norming experiment (reported in the Method section below). If the effects of accessibility and givenness shown in Experiments 1 and 2 resulted from verbal WM processes, participants in Experiment 3 should show a reduced tendency to produce given-new ordering effects in the verbal but not the spatial WM-load condition. The opposite pattern was predicted for the mental rotation task, in which the spatial WM load should impair performance relative to the verbal load. However, if these effects reflected the relative complexity of the load trials rather than the memory load per se, there should be no effect of the type of WM load (on either the sentence production or the spatial task), as both types of WM load should lead to a reduction in attentional control.

\section{Method}

Participants. Fifty-five students at the University of California, San Diego, participated in exchange for class credit. Data were excluded from six participants who did not produce analyzable sentences on a majority of trials and from one participant because of an experimenter error. Data were excluded from nine additional participants who showed particularly poor performance on spatial WM load recall (these participants recalled at least part of a WM load on fewer than $40 \%$ of the spatial load trials).

Materials and design. The experimental design and materials used in the previous experiments were used in the main part of Experiment 3. In addition, a spatial load and a spatial task (letter rotation) were created, and 26 additional verbal load words were selected and digitally recorded.

Spatial WM load. The spatial WM load was based on Ichikawa's $(1981,1983)$ dot-in-matrix patterns (see also Miyake, Friedman, Rettinger, Shah, \& Hegarty, 2001). These patterns are fiveby-five grids with dots randomly assigned to spaces in the grid. Dot configurations that were duplicates or that formed systematic patterns were eliminated (Ichikawa, 1981; Miyake et al., 2001), and these patterns were presented for $750 \mathrm{~ms}$ on a computer screen. This duration was chosen following Miyake et al. (2001), who found $750 \mathrm{~ms}$ to be a presentation brief enough to discourage verbal or other idiosyncratic coding strategies (e.g., "two over, three down") while still allowing enough exposure to encode the pattern into spatial WM.

A norming experiment was conducted with a separate group of 10 participants in order to determine the appropriate difficulty of

\footnotetext{
${ }^{2}$ Because of participants' perfect accuracy in the given-new ordering conditions of Experiments 2 and 3, it is not possible to estimate significance based on a Wald $z$ test. Thus, these analyses of accuracy data are instead reported with likelihood ratio tests based on single degree of freedom model comparisons (Agresti, 2002). Although this test may be anticonservative (Pinheiro \& Bates, 2000) it was deemed acceptable in these situations, as the accuracy differences in these experiments are not particularly subtle.

3 This is also likely to be quite different for signed languages (cf. Wilson \& Emmorey, 1997, 2003).
} 
this dot memory task. On each trial of this norming task, participants saw either a verbal (two-word) or a spatial (dot-in-matrix pattern) memory load and then saw a sentence on the computer screen, which they were instructed to say aloud. The sentence disappeared as soon as the participants started to speak (triggered by a head-worn microphone connected to a PsyScope button box); thus, participants had to process the sentences sufficiently to produce them from memory. Finally, participants either said aloud the verbal load or marked the location of the dots on an answer sheet containing several five-by-five matrix grids. The verbal load trials used the 18 two-word verbal load stimuli from Experiments 1 and 2, and the spatial load trials were 48 dot-in-matrix patterns containing 2, 3, 4, or 5 dots (12 patterns of each difficulty). The 66 sentences were mostly intransitive or predicate-adjective structures. Two lists were created that randomly paired sentences with load stimuli, with the constraint that the verbal load stimuli were not paired with sentences to which they shared any obvious semantic or phonological relationship. Trial order was randomly ordered within each list.

On average, participants accurately recalled both words on $47.2 \%$ of the verbal-load trials and accurately recalled the dot pattern on $52 \%$ of the two-dot trials, $25 \%$ of the three-dot trials, $8 \%$ of the four-dot trials, and $7 \%$ of the five-dot trials. Matchedpairs $t$ tests revealed that performance on the verbal load and on the two-dot spatial load did not differ significantly, $t(9)=0.53$, whereas performance on the verbal load was significantly better than performance on the three-dot, $t(9)=-3.71, p<.005$; four-dot, $t(9)=-6.87, p<.001$; and five-dot, $t(9)=-5.96, p<$ .005 , spatial load trials. Because these data suggest that a two-dot pattern is equivalently difficult to the two-word verbal load, 34 unique two-dot patterns were created (as above) to serve as the spatial load in Experiment 3.

Letter rotation task. The spatial processing task was a letter rotation task adapted from one used in Shah and Miyake (1996). ${ }^{4}$ On each trial, participants saw a series of two to five capital letters (from the set of $F, J, L, P$, or $R$ ) that were either normal or mirror imaged and that were presented in a noncanonical orientation (rotated $45^{\circ}, 90^{\circ}, 135^{\circ}, 180^{\circ}, 225^{\circ}, 270^{\circ}$, or $315^{\circ}$ from upright). Participants' task was to press the right/green button on the buttonbox to indicate if the letter was "normal" or the left/red button if the letter was "mirror imaged" as quickly and accurately as possible. There was a practice block of 30 upright letters (three normal and three mirrored versions of each of the six letters, presented in random order) and then a second practice block with three trials of two rotated letters per trial. There were 24 experimental trials, in four blocks of six trials each, which progressed from two to five letters per trial.

Procedure. Experiment 3 consisted of two parts. The procedure of the first part was identical to that of Experiment 2 except that the no-load trials were replaced with trials requiring maintenance of a spatial WM load. Thus, Experiment 3 manipulated givenness (theme or goal) and WM task (verbal or spatial). On each spatial-load trial, participants first pressed a button and saw a five-by-five grid with dots in two of the squares for $750 \mathrm{~ms}$ on the computer screen. The experimenter then asked a question (e.g., What's going on with the pirate and the book?). The participant responded by describing the relevant picture from the poster on the wall and then indicating the two dot locations on a five-by-five grid printed on a paper answer sheet. The procedure for the verbal load trials was the same, except that the experimenter read aloud the two unrelated load words, which the participant recalled aloud at the end of the trial (just as on the load trials in Experiment 2).

In the second part of Experiment 3, participants judged whether letters at different rotations were normal or mirror imaged while they maintained either a verbal or a spatial WM load (just as in the sentence production task). A practice block familiarized participants with the normal/mirrored distinction, and a second practice block familiarized participants with the rotation task while under verbal and spatial loads (with one verbal load and two spatial load practice trials). On each trial of the second practice block and of the experimental blocks, participants either saw a two-dot pattern for $750 \mathrm{~ms}$ or heard two unrelated words through a speaker next to the computer; made normal/mirror judgments for 2, 3, 4, or 5 rotated letters; and then recalled aloud the verbal load or marked the spatial load dot locations on an answer grid.

\section{Analysis, Results, and Discussion}

Sentence production task. As in the previous experiments, participants' sentences from the picture-description task were transcribed and coded as prepositional datives or double-object datives. Trials in which participants did not produce a dative sentence or did not produce both postverbal noun phrases were excluded from the analysis, resulting in the exclusion of $8.1 \%$ of all critical trials $(9.0 \%$ of trials in the verbal load condition and $7.3 \%$ of trials in the spatial load condition). Trials on which participants did not correctly remember at least one word of the verbal load or one dot location of the spatial load were also excluded, leading to the exclusion of an additional $13.2 \%$ of all critical trials $(6.8 \%$ of verbal load trials and $19.4 \%$ of spatial load trials).

Figure 3 shows the proportion of prepositional datives produced as a function of cue givenness (theme or goal) and WM task (verbal vs. spatial). A significant effect of cue givenness reflected participants' tendency to produce given information before new information $(b=2.92, S E=0.33, z=8.97, p<.001)$. This effect interacted with WM task $(b=-1.29, S E=0.57, z=-2.28, p<$ $.05)$, reflecting the reduced use of given-new ordering when under verbal load (when participants produced prepositional datives $20 \%$ more often following theme than goal mention) compared to when under spatial load (when participants produced prepositional datives $31 \%$ more often following theme than goal mention).

As in Experiment 2, participants were more accurate at recalling the WM load when they produced given-new ordering (recalling at least one word or dot on every given-new trial) than when they produced new-given ordering (recalling at least one word or dot on only $75 \%$ of new-given trials; $\chi^{2}=216.19, p<.001$ ). This was expected for the verbal load because not producing given information early presumably results in a greater chance for that information to interfere with retrieval of the WM load words. Unexpectedly, spatial WM load accuracy was also worse on trials in which participants produced new-given ordering (i.e., the effect of ordering on accuracy did not interact with load type; $\left.\chi^{2}<1\right)$. One might imagine that trials where speakers produced new-given ordering were trials in which production was relatively more difficult and time consuming, and this took attention away from

\footnotetext{
${ }^{4}$ Thanks to Naomi Friedman for helpful advice regarding this task.
} 


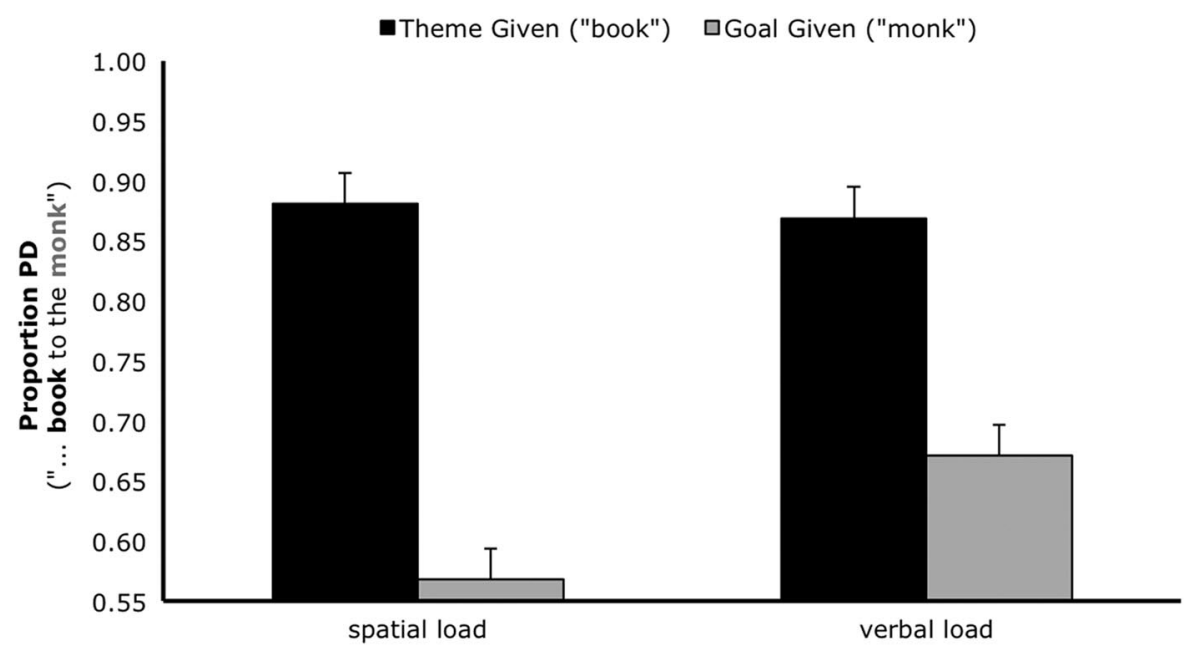

Figure 3. Proportion of prepositional dative (PD) sentences produced in Experiment 3 as a function of cue type (i.e., which postverbal argument was given information: theme or goal) and type of working memory task (spatial load vs. verbal load). Note that the $y$-axis does not start at zero. Error bars represent standard error.

maintenance of the spatial WM load. But if given-new ordering results from verbal WM processes, it is not clear why production of given-new ordering would reduce demand on domain-general attentional control. And if given-new ordering reflects the general ability to control attention, it is then mysterious that the spatial WM load did not appear to affect given-new ordering. Of course, without a no-load condition in Experiment 3, it is possible that the spatial load did subtly influence given-new ordering, leaving open the possibility that both verbal WM and a more general form of cognitive control play a role in accessibility effects (cf. Swets, Desmit, Hambrick, \& Ferreira, 2007; Unsworth \& Spillers, 2010).

Letter rotation task. Trials in which participants did not correctly remember the WM load were excluded from the analysis according to the same criteria as in the sentence production task, leading to the exclusion of $15.2 \%$ of all trials. Participants seem to have found the spatial load more difficult than the verbal load, as these criteria led to the exclusion of $30.3 \%$ of trials in the spatial load condition but no trials in the verbal load condition. Additionally, reaction times deviating more than two standard deviations from each participant's mean reaction time were excluded from the analysis, leading to the exclusion of an additional $3.0 \%$ of all trials (3.4\% of trials in the spatial load condition and $2.6 \%$ of trials in the verbal load condition). Reaction times were analyzed with a linear mixed-effects model treating subject as a random effect and WM task as a fixed effect. Statistical significance was assessed with Markov chain Monte Carlo sampling as implemented in the languageR package (Baayen, 2008).

Although the accuracy of letter rotation judgments did not differ as a function of load, reaction times did: Participants were about 70 ms slower to make letter rotation judgments when under a spatial WM load than when under a verbal WM load, as shown by a significant effect of WM task $(b=-65.53 \mathrm{~ms}, S E=21.61 \mathrm{~ms}, t=$ $-3.03, p<.01)$.

Experiment 3 provides evidence that given-new ordering depends on verbal WM because, compared to a load on spatial WM, a concurrent load on verbal WM led to decreased use of given-new ordering. This shows that the effect of a verbal WM load on sentence production found here and in the previous experiments is not attributable to the dual-task nature of the load trials nor to the overall increased difficulty in the WM load trials. If anything, the spatial WM load seems to have been more difficult overall, as evidenced by how often participants were unable to remember the spatial load relative to the verbal load. Furthermore, the opposite pattern was found in a letter rotation task that requires spatial processing, namely, that the spatial WM load led to worse performance than the verbal WM load. This finding shows that the spatial load was difficult enough to influence processing and adds further support to the distinction between verbal and spatial WM processes. There was an effect of chosen word order on spatial load recall, which shows that general attentional control mechanisms may play some role in accessibility effects (cf. Swets et al., 2007). However, the dissociation between effects of verbal and spatial WM load on production of given-new ordering suggests that verbal WM is the primary cognitive mechanism underlying accessibility effects and given-new ordering.

\section{General Discussion}

These experiments show that accessibility effects interact with manipulations of WM load, thereby confirming the suggestion that accessibility effects can result from a pressure to avoid maintaining otherwise ready-to-produce material in WM (Bock, 1982; Ferreira, 1996). It should be noted that the manipulations of accessibility used here were of memory-based accessibility; future work should examine if other forms of accessibility and givenness (e.g., accessibility due to animacy [McDonald et al., 1993] or givenness due to definite reference [Grieve, 1973]) also interact with manipulations of verbal WM. These data also support the idea that given-new ordering can arise as a function of the accessibility of given information in speakers' verbal WM (Arnold et al., 2000; Bock \& Irwin, 1980; Branigan et al., 2003).

These findings have a number of implications for the role of WM in language production. First, the type of WM underlying accessibility effects is not specific to syntactic production. It is still 
possible that grammatical encoding relies on a dedicated WM system, as accessibility effects influence syntactic choice somewhat indirectly (i.e., by influencing the mapping of lexical content onto syntax). Nevertheless, these results, along with work showing retrieval-based interference in other aspects of production (in particular, in agreement production; Badecker \& Kuminiak, 2007), suggest that sentence production does not rely on a dedicated pool of memory resources, as has been claimed to be the case for syntactic parsing (e.g., Caplan \& Waters, 1999).

Instead, syntactic choice was influenced by nonsyntactic pressure on WM from the maintenance of a concurrent verbal WM load. It is interesting that the way that a verbal WM load influenced syntactic choice was by leading to a reduction, rather than an increase, in accessibility effects and given-new ordering. This is contrary to the motivation of accessibility effects as a release valve for WM. By that account, a WM load should have coexisted in a limited-capacity WM workspace along with the cued noun phrase (i.e., the made-accessible information). Thus, a concurrent WM load should have added pressure on WM, which would increase the utility of freeing capacity by producing buffered information as early as possible (in this case, by choosing a syntactic structure allowing for early mention of the cued noun phrase).

Instead, these data showed that a verbal WM load leads to a reduction in accessibility effects. This pattern suggests that the crucial limiting factor in WM is interference rather than capacity limits. It fits with models in which WM consists of a system of limited attentional focus, with a maximum capacity of only one to four items plus a cue-based search mechanism for items displaced from this attentional focus (e.g., Cowan, 2001; Lewis, 1996; McElree, 2001; Unsworth \& Engle, 2007). Accessibility effects, then, emerge when lexical items (i.e., lemmas) that are part of this limited attentional focus can be produced early, thereby freeing up attentional resources for other purposes. However, when a WM load displaces information from focus, that displaced lexical information must be re-retrieved, at which point it is subject to interference both from items currently in focus and from other cue-relevant information (cf. Badecker \& Kuminiak, 2007; Fedorenko, Gibson, \& Rohde, 2006; Gordon, Hendrick, \& Levine, 2002; Lewis \& Vasishth, 2005; A. E. Martin \& McElree, 2009; Van Dyke, 2007; Wagers, Lau, \& Phillips, 2009). The fact that effects of givenness were greater than effects of accessibility on syntactic choice emerges simply from the assumption that givenness exerts a stronger pull on the focus of attention than does accessibility alone.

Still, the role WM plays in sentence production (at least as far as accessibility effects are concerned) is not so general a mechanism as is attentional control (e.g., Cowan et al., 2005; Kane et al., 2004; McCabe et al., 2010; Vergauwe et al., 2010). This conclusion comes from evidence that although a verbal WM load led to a reduction in given-new ordering, a load on spatial WM did not. In fact, the given-new ordering effects in the spatial WM-load condition of Experiment 3 were numerically the largest effects across all experiments. This contrast between the verbal and spatial WM load also addresses an alternative account for many other demonstrations of domain-general WM effects on syntactic processing, namely, that the load condition imposes a dual task and this task switching actually leads to the effects purported to be WM related (for critiques of this sort, see Caplan \& Waters, 1999).
The discussion thus far has assumed that the verbal WM load interfered with either the maintenance or the retrieval of the accessible lexical item (i.e., that the WM load either made it difficult to keep information sufficiently active to warrant early mention or led to increased interference at the point of retrieving that otherwise accessible item). However, a plausible alternative is that the WM load interfered with the encoding of the accessible item. By this account, the WM load caused the cued information to be less thoroughly processed, causing that information to sometimes be insufficiently accessible to warrant early mention. The data presented here cannot distinguish between these accounts because, in these experiments, the WM load always preceded the manipulation of accessibility. However, under either account, grammatical encoding processes depend on verbal WM mechanisms; therefore, this distinction does not detract from the main conclusions that accessibility effects and given-new ordering result from constraints on general processes of interference in verbal WM.

An additional point deserves mention, namely, that speakers overwhelmingly preferred to use prepositional dative structures in these data $(81 \%$ of all dative sentences produced in these three experiments were prepositional datives). This is somewhat surprising because data from corpora of naturally produced language suggest that prepositional datives and double-object datives are about equally common in English (e.g., Zhong, Stent, \& Swift, 2006). Although this preponderance of prepositional datives was unexpected, there is no reason to assume it is related to the interaction between accessibility effects and WM load. Thus, it should not detract from the main pattern of results.

\section{Conclusions}

Because speaking requires the production of nonlinear conceptual information as a linear order of words, speakers often must maintain information that is otherwise ready to be produced. The experiments reported here show that this process is susceptible to general processes of interference in verbal WM: Speakers help reduce the potential for interference in WM by relying on the flexibility afforded by the grammar and choosing syntactic structures that allow information to be produced as it becomes accessible. The fact that accessibility effects and given-new ordering were reduced when under verbal WM load shows that WM processes in sentence production are vulnerable to similarity-based interference. This supports retrieval models of WM that point to limitations due not to capacity (as in, e.g., Baddeley, 1986; Ruchkin, Grafman, Cameron, \& Berndt, 2003) but rather to interference (Cowan, 2001, 2005; Lewis, 1996; Lewis, Vasishth, \& Van Dyke, 2006; McElree, 2001; Oberauer, 2002; Unsworth \& Engle, 2007). This claim also fits with evidence that similarity-based interference is critical in other aspects of syntactic production (Badecker \& Kuminiak, 2007) and parsing (e.g., Gordon et al., 2002; Wagers et al., 2009).

\section{References}

Agresti, A. (2002). Categorical data analysis (2nd ed.). New York, NY: Wiley.

Ariel, M. (1991). The function of accessibility in a theory of grammar. Journal of Pragmatics, 16, 443-463. doi:10.1016/03782166(91)90136-L 
Arnold, J. E. (2010). How speakers refer: The role of accessibility. Language and Linguistics Compass, 4, 187-203. doi:10.1111/j.1749818X.2010.00193.X

Arnold, J. E., \& Griffin, Z. M. (2007). The effect of additional characters on choice of referring expression: Everyone counts. Journal of Memory and Language, 56, 521-536. doi:10.1016/j.jml.2006.09.007

Arnold, J. E., Wasow, T., Losongco, A., \& Ginstrom, R. (2000). Heavyness vs. newness: The effects of structural complexity and discourse status on constituent ordering. Language, 76, 28-55. doi:10.2307/417392

Baayen, R. H. (2008). languageR: Data sets and functions with Analyzing linguistic data: A practical introduction to statistics ( $\mathrm{R}$ package Version 0.953). Retrieved from http://cran.r-project.org/web/packages/ languageR/index.html

Baddeley, A. D. (1986). Working memory. Oxford, England: Oxford University Press.

Baddeley, A. D., \& Hitch, G. J. (1974). Working memory. In G. A. Bower (Ed.), Recent advances in learning and motivation (Vol. 8, pp. 47-90). New York, NY: Academic Press.

Badecker, W., \& Kuminiak, F. (2007). Morphology, agreement and working memory retrieval in sentence production: Evidence from gender and case in Slovak. Journal of Memory and Language, 56, 65-85. doi: 10.1016/j.jml.2006.08.004

Bates, D. M., \& Maechler, M. (2009). lme4: Linear mixed-effects models using S4 classes (R package version 0.999375-31) [Computer software]. Retrieved from http://CRAN.R-project.org/package $=1 \mathrm{me} 4$

Belke, E. (2008). Effects of working memory load on lexical-semantic encoding in language production. Psychonomic Bulletin \& Review, 15, 357-363. doi:10.3758/PBR.15.2.357

Bock, J. K. (1977). The effect of a pragmatic presupposition on syntactic structure in question answering. Journal of Verbal Learning and Verbal Behavior, 16, 723-734. doi:10.1016/S0022-5371(77)80031-5

Bock, J. K. (1982). Toward a cognitive psychology of syntax: Information processing contributions to sentence formulation. Psychological Review, 89, 1-47. doi:10.1037/0033-295X.89.1.1

Bock, J. K. (1986). Meaning, sound, and syntax: Lexical priming in sentence production. Journal of Experimental Psychology: Learning, Memory, and Cognition, 12, 575-586. doi:10.1037/0278-7393.12.4.575

Bock, J. K. (1987). An effect of the accessibility of word forms on sentence structures. Journal of Memory and Language, 26, 119-137. doi: 10.1016/0749-596X(87)90120-3

Bock, J. K. (1995). Sentence production: From mind to mouth. In J. L. Miller \& P. D. Eilmas (Eds.), Handbook of perception and cognition: Vol. 11. Speech, language, and communication (pp. 181-216). Orlando, FL: Academic Press.

Bock, J. K., \& Cutting, J. C. (1992). Regulating mental energy: Performance units in language production. Journal of Memory and Language, 31, 99-127. doi:10.1016/0749-596X(92)90007-K

Bock, J. K., \& Irwin, D. E. (1980). Syntactic effects of information availability in sentence production. Journal of Verbal Learning and Verbal Behavior, 19, 467-484. doi:10.1016/S0022-5371(80)90321-7

Bock, J. K., \& Warren, R. K. (1985). Conceptual accessibility and syntactic structure in sentence formulation. Cognition, 21, 47-67. doi:10.1016/ 0010-0277(85)90023-X

Branigan, H. P., McLean, J. F., \& Reeve, H. M. (2003). Something old, something new: Addressee knowledge and the given-new contract. In R. Alterman \& D. Kirsh (Eds.), Proceedings of the 25th Annual Meeting of the Cognitive Science Society (pp. 180-185). Boston, MA: Cognitive Science Society.

Bresnan, J., Cueni, A., Nikitina, T., \& Baayen, R. H. (2007). Predicting the dative alternation. In G. Boume, I. Kraemer, \& J. Zwarts (Eds.), Cognitive foundations of interpretation (pp. 69-94). Amsterdam: Royal Netherlands Academy of Science.

Caplan, D., \& Waters, G. S. (1999). Verbal working memory and sentence comprehension. Behavioral and Brain Sciences, 22, 77-94. doi:10.1017/ S0140525X99001788

Chafe, W. L. (1976). Givenness, contrastiveness, definiteness, subjects, topics, and point of view. In C. Li (Ed.), Subject and topic (pp. 25-55). New York, NY: Academic Press.

Chatterjee, A., Southwood, M. H., \& Basilico, D. (1999). Verbs, events and spatial representations. Neuropsychologia, 37, 395-402. doi:10.1016/ S0028-3932(98)00108-0

Clark, H. H., \& Haviland, S. E. (1977). Comprehension and the given-new contract. In R. Freedle (Ed.), Discourse production and comprehension (pp. 1-40). New York, NY: Ablex.

Cohen, J. D., MacWhinney, B., Flatt, M., \& Provost, J. (1993). PsyScope An interactive graphic system for designing and controlling experiments in the psychology laboratory using Macintosh computers. Behavior Research Methods, Instruments, \& Computers, 25, 257-271. doi: 10.3758/BF03204507

Cowan, N. (1999). An embedded-processes model of working memory. In A. Miyake \& P. Shah (Eds.), Models of working memory: Mechanisms of active maintenance and executive control (pp. 62-101). New York, NY: Cambridge University Press.

Cowan, N. (2001). The magical number 4 in short-term memory: A reconsideration of mental storage capacity. Behavioral and Brain Sciences, 24, 87-114. doi:10.1017/S0140525X01003922

Cowan, N. (2005). Working memory capacity. New York, NY: Psychology Press.

Cowan, N., Elliott, E. M., Saults, J. S., Morey, C. C., Mattox, S., Hismjatullina, A., \& Conway, A. R. A. (2005). On the capacity of attention: Its estimation and its role in working memory and cognitive aptitudes. Cognitive Psychology, 51, 42-100. doi:10.1016/j.cogpsych.2004.12.001

Crowder, R. G. (1982). The demise of short-term memory. Acta Psychologica, 50, 291-323. doi:10.1016/0001-6918(82)90044-0

Crowder, R. G. (1993). Short-term memory: Where do we stand? Memory \& Cognition, 21, 142-145. doi:10.3758/BF03202725

Daneman, M. (1991). Working memory as a predictor of verbal fluency. Journal of Psycholinguistic Research, 20, 445-464. doi:10.1007/ BF01067637

Daneman, M., \& Green, I. (1986). Individual differences in comprehending and producing words in context. Journal of Memory and Language, 25, 1-18. doi:10.1016/0749-596X(86)90018-5

Davelaar, E. J., Goshen-Gottstein, Y., Ashkenazi, A., Haarmann, H. J., \& Usher, M. (2005). The demise of short-term memory revisited: Empirical and computational investigations of recency effects. Psychological Review, 112, 3-42. doi:10.1037/0033-295X.112.1.3

Davidson, D. J., Zacks, R. T., \& Ferreira, F. (2003). Age preservation of the syntactic processor in production. Journal of Psycholinguistic Research, 32, 541-566. doi:10.1023/A:1025402517111

Fedorenko, E., Gibson, E., \& Rohde, D. (2006). The nature of working memory capacity in sentence comprehension: Evidence against domainspecific working memory resources. Journal of Memory and Language, 54, 541-553. doi:10.1016/j.jml.2005.12.006

Fedorenko, E., Gibson, E., \& Rohde, D. (2007). The nature of working memory in linguistic, arithmetic and spatial integration processes. Journal of Memory and Language, 56, 246-269. doi:10.1016/ j.jml.2006.06.007

Ferreira, V. S. (1996). Is it better to give than to donate? Syntactic flexibility in language production. Journal of Memory and Language 35, 724-755. doi:10.1006/jmla.1996.0038

Ferreira, V. S., \& Slevc, L. R. (2007). Grammatical encoding. In M. Gareth Gaskell (Ed.), The Oxford handbook of psycholinguistics (pp. 453-469). Oxford, England: Oxford University Press.

Ferreira, V. S., \& Yoshita, H. (2003). Given-new ordering effects on the production of scrambled sentences in Japanese. Journal of Psycholinguistic Research, 32, 669-692. doi:10.1023/A:1026146332132

Friedman, N. P., \& Miyake, A. (2000). Differential roles for visuospatial 
and verbal working memory in situation model construction. Journal of Experimental Psychology: General, 129, 61-83. doi:10.1037/00963445.129.1.61

Glanzer, M., \& Cunitz, A. R. (1966). Two storage mechanisms in free recall. Journal of Verbal Learning and Verbal Behavior, 5, 351-360. doi:10.1016/S0022-5371(66)80044-0

Gordon, P. C., Hendrick, R., \& Levine, W. H. (2002). Memory-load interference in syntactic processing. Psychological Science, 13, 425430. doi:10.1111/1467-9280.00475

Grieve, R. (1973). Definiteness in discourse. Language and Speech, 16, 365-372.

Guérard, K., \& Tremblay, S. (2008). Revisiting evidence for modularity and functional equivalence across verbal and spatial domains in memory. Journal of Experimental Psychology: Learning, Memory, and Cognition, 34, 556-569. doi:10.1037/0278-7393.34.3.556

Gundel, J. K. (1988). Universals of topic-comment structure. In M. Hammond, E. A. Moravcsik, \& J. R. Wirth (Eds.), Studies in syntactic typology (pp. 209-239). Philadelphia, PA: Benjamins.

Halliday, M. A. K. (1970). Language structure and language function. In J. Lyons (Ed.), New horizons in linguistics (pp. 140-165). New York, NY: Penguin Books.

Halliday, M. A. K. (1994). The construction of knowledge and value in the grammar of scientific discourse: With reference to Charles Darwin's The Origin of Species. In M. Coulthard (Ed.), Advances in written text analysis (pp. 136-156). London, England: Routledge.

Hartsuiker, R. J., \& Barkhuysen, P. N. (2006). Language production and working memory: The case of subject-verb agreement. Language and Cognitive Processes, 21, 181-204. doi:10.1080/01690960400002117

Horton, W. S., \& Gerrig, R. J. (2005a). Conversational common ground and memory processes in language production. Discourse Processes, 40, 1-35. doi:10.1207/s15326950dp4001_1

Horton, W. S., \& Gerrig, R. J. (2005b). The impact of memory demands on audience design during language production. Cognition, 96, 127-142. doi:10.1016/j.cognition.2004.07.001

Ichikawa, S. (1981). Rated ease of memorization of dot-in-matrix patterns: Multiple regression analysis by physical variables which describe configuration of dots. Japanese Psychological Research, 23, 69-78.

Ichikawa, S. (1983). Verbal memory span, visual memory span, and their correlations with cognitive tasks. Japanese Psychological Research, 25, 173-180.

Jackendoff, R. (1972). Semantic interpretation in generative grammar. Cambridge, MA: MIT Press

Jackendoff, R. (2002). Foundations of language: Brain, meaning, grammar, evolution. New York, NY: Oxford University Press.

Just, M. A., \& Carpenter, P. A. (1992). A capacity theory of comprehension: Individual differences in working memory. Psychological Review, 99, 122-149. doi:10.1037/0033-295X.99.1.122

Kane, M. J., Hambrick, D. Z., Tuholski, S. W., Wilhelm, O., Payne, T. W., \& Engle, R. W. (2004). The generality of working memory capacity: A latent variable approach to verbal and visuospatial memory span and reasoning. Journal of Experimental Psychology: General, 133, 189217. doi:10.1037/0096-3445.133.2.189

Kellogg, R. T. (2004). Working memory components in written sentence generation. American Journal of Psychology, 117, 341-361. doi: $10.2307 / 4149005$

Levelt, W. J. M., \& Maassen, B. (1981). Lexical search and order of mention in sentence production. In W. Klein \& W. Levelt (Eds.), Crossing the boundaries in linguistics (pp. 221-252). Dordrecht, Germany: Reidel.

Levelt, W. J. M., Roelofs, A., \& Meyer, A. S. (1999). A theory of lexical access in speech production. Behavioral and Brain Sciences, 22, 1-38. doi:10.1017/S0140525X99001776

Lewis, R. L. (1996). Interference in short-term memory: The magical number two (or three) in sentence processing. Journal of Psycholinguistic Research, 25, 93-115. doi:10.1007/BF01708421

Lewis, R. L., \& Vasishth, S. (2005). An activation-based model of sentence processing as skilled memory retrieval. Cognitive Science, 29, 375-419. doi:10.1207/s15516709cog0000_25

Lewis, R. L., Vasishth, S., \& Van Dyke, J. A. (2006). Computational principles of working memory in sentence comprehension. Trends in Cognitive Sciences, 10, 447-454. doi:10.1016/j.tics.2006.08.007

Martin, A. E., \& McElree, B. (2009). Memory operations that support language comprehension: Evidence from verb-phrase ellipsis. Journal of Experimental Psychology: Learning, Memory, and Cognition, 35, 12311239. doi: $10.1037 / \mathrm{a} 0016271$

Martin, R. C., \& Freedman, M. L. (2001). Short-term retention of lexicalsemantic representations: Implications for speech production. Memory, 9, 261-280. doi:10.1080/09658210143000173

Martin, R. C., Lesch, M. F., \& Bartha, M. C. (1999). Independence of input and output phonology in word processing and short-term memory. Journal of Memory and Language, 41, 3-29. doi:10.1006/ jmla.1999.2637

Martin, R. C., Miller, M., \& Vu, H. (2004). Lexical-semantic retention and speech production: Further evidence from normal and brain-damaged participants for a phrasal scope of planning. Cognitive Neuropsychology, 21, 625-644. doi:10.1080/02643290342000302

McCabe, D. P., Roediger, H. L., McDaniel, M. A., Balota, D. A., \& Hambrick, D. Z. (2010). The relationship between working memory capacity and executive functioning: Evidence for a common executive attention construct. Neuropsychology, 24, 222-243. doi:10.1037/ a0017619

McDonald, J. L., Bock, K., \& Kelly, M. H. (1993). Word and world order: Semantic, phonological, and metrical determinants of serial position. Cognitive Psychology, 25, 188-230. doi:10.1006/cogp.1993.1005

McElree, B. (2001). Working memory and focal attention. Journal of Experimental Psychology: Learning, Memory, and Cognition, 27, 817835. doi:10.1037/0278-7393.27.3.817

Miyake, A., Friedman, N. P., Rettinger, D. A., Shah, P., \& Hegarty, M (2001). How are visuospatial working memory, executive functioning, and spatial abilities related? A latent-variable analysis. Journal of Experimental Psychology: General, 130, 621-640. doi:10.1037/00963445.130.4.621

Oberauer, K. (2002). Access to information in working memory: Exploring the focus of attention. Journal of Experimental Psychology: Learning, Memory, and Cognition, 28, 411-421. doi:10.1037/0278-7393.28.3.411

Pashler, H. (1994). Dual-task interference in simple tasks: Data and theory. Psychological Bulletin, 116, 220-244. doi:10.1037/00332909.116.2.220

Pinheiro, J. C., \& Bates, D. M. (2000). Mixed-effects models in $S$ and $S$-PLUS. New York, NY: Springer.

R Development Core Team. (2009). R: A language and environment for statistical computing (Version 2.9.1) [Computer software]. Retrieved from http://www.R-project.org

Richardson, D. C., Spivey, M. J., Barsalou, L. W., \& McRae, K. (2003). Spatial representations activated during real-time comprehension of verbs. Cognitive Science, 27, 767-780. doi:10.1207/ s15516709 $\operatorname{cog} 2705 \_4$

Roßnagel, C. (2000). Cognitive load and perspective-taking: Applying the automatic-controlled distinction to verbal communication. European Journal of Social Psychology, 30, 429-445. doi:10.1002/(SICI)10990992(200005/06)30:3<429::AID-EJSP3>3.0.CO;2-V

Roßnagel, C. (2004). Lost in thought: Cognitive load and the processing of addressees' feedback in verbal communication. Experimental Psychology, 51, 191-200. doi:10.1027/1618-3169.51.3.191

Ruchkin, D. S., Grafman, J., Cameron, K., \& Berndt, R. S. (2003). Working memory retention systems: A state of activated long-term 
memory. Behavioral and Brain Sciences, 26, 709-728. doi:10.1017/ S0140525X03000165

Shah, P., \& Miyake, A. (1996). The separability of working memory resources for spatial thinking and language processing: An individual differences approach. Journal of Experimental Psychology: General, 125, 4-27. doi:10.1037/0096-3445.125.1.4

Smyth, R. H., Prideaux, G. D., \& Hogan, J. T. (1979). The effect of context on dative position. Lingua, 47, 27-42. doi:10.1016/00243841(79)90065-2

Swets, B., Desmit, T., Hambrick, D. Z., \& Ferreira, F. (2007). The role of working memory in syntactic ambiguity resolution: A psychometric approach. Journal of Experimental Psychology: General, 136, 64-81. doi:10.1037/0096-3445.136.1.64

Unsworth, N., \& Engle, R. W. (2007). The nature of individual differences in working memory capacity: Active maintenance in primary memory and controlled search from secondary memory. Psychological Review, 114, 104-132. doi:10.1037/0033-295X.114.1.104

Unsworth, N., \& Spillers, G. J. (2010). Working memory capacity: Attention control, secondary memory, or both? A direct test of the dualcomponent model. Journal of Memory and Language, 62, 392-406. doi:10.1016/j.jml.2010.02.001

Van Dyke, J. A. (2007). Interference effects from grammatically unavailable constituents during sentence processing. Journal of Experimental Psychology: Learning, Memory, and Cognition, 33, 407-430. doi: 10.1037/0278-7393.33.2.407

Vergauwe, E., Barrouillet, P., \& Camos, V. (2010). Do mental processes share a domain-general resource? Psychological Science, 21, 384-390. doi:10.1177/0956797610361340

Wagers, M. W., Lau, E. F., \& Phillips, C. (2009). Agreement attraction in comprehension: Representations and processes. Journal of Memory and Language, 61, 206-237. doi:10.1016/j.jml.2009.04.002

Wagner, V., Jescheniak, J. D., \& Schriefers, H. (2010). On the flexibility of grammatical advance planning during sentence production: Effects of cognitive load on multiple lexical access. Journal of Experimental Psychology: Learning, Memory, and Cognition, 36, 423-440. doi: $10.1037 / \mathrm{a} 0018619$

Wilson, M., \& Emmorey, K. (1997). A visuospatial "phonological loop" in working memory: Evidence from American Sign Language. Memory \& Cognition, 25, 313-320. doi:10.3758/BF03211287

Wilson, M., \& Emmorey, K. (2003). The effect of irrelevant visual input on working memory for sign language. Journal of Deaf Studies and Deaf Education, 8, 97-103. doi:10.1093/deafed/eng010

Zhong, H., Stent, A., \& Swift, M. (2006). Modeling the dative alternation with automatically extracted features. In Proceedings of the workshop on statistical and empirical approaches for spoken dialogue systems (Tech. Rep. WS-06-14). Menlo Park, CA: American Association for Artificial Intelligence.

Received April 15, 2010

Revision received May 10, 2011

Accepted May 16, 2011

\section{E-Mail Notification of Your Latest Issue Online!}

Would you like to know when the next issue of your favorite APA journal will be available online? This service is now available to you. Sign up at http://notify.apa.org/ and you will be notified by e-mail when issues of interest to you become available! 